\title{
An Interpretation of the Continuous Adaptation of the Self/Environment Process
}

\author{
Chris Francovich, Gonzaga University, WA, USA
}

\begin{abstract}
Insights into the nondual relationship of organism and environment and their processual nature have resulted in numerous efforts at understanding human behavior and motivation from a holistic and contextual perspective. Meadian social theory, cultural historical activity theory (CHAT), ecological psychology, and some interpretations of complexity theory persist in relating human activity to the wider and more scientifically valid view that a process metaphysics suggests. I would like to articulate a concept from ecological psychology - that of the affordance, and relate it to aspects of phenomenology and neuroscience such that interpretations of the self, cognition, and the brain are understood as similar to interpretations of molar behaviors exhibited in social processes. Experience with meditation as a method of joining normal reflective consciousness with 'awareness' is described and suggested as a useful tool in coming to better understand the nondual nature of the body.
\end{abstract}

Keywords: The Self, Ecological Psychology, Non-dual Models of the Self, Organism/Environment Relations

$\mathrm{E}$ XPERIENTIAL INSIGHTS AND scientific discoveries into the nondual relationship of organism and environment ${ }^{1}$ and the assumed processual nature of that relationship have resulted in numerous interpretations of human behavior, experience, and thought from both convergent 'objectivist' perspectives and from more explicitly interpretive contextual perspectives. For example, modern physical theories (e.g., Quantum Physics), phenomenology, Meadian social theory, cultural historical activity theory (CHAT), ecological psychology, some interpretations of complexity theory, and numerous traditions from eastern, western, and indigenous perspectives persist in relating human behavior or activity and experience to the wider view that a process metaphysics suggests.

Taking this view or interpretation of experience, thought, and activity seriously has implications for personal, organizational, and global situations and events. The practical and ideological separations and divisions resulting from disciplinary specializations around the definitions and understanding of, for example, the self, relationships, communities, cultures, or ideologies have a cumulative result that is evident in social, ecological, and political crisis on a global scale. Specialization and the segregation of knowledge from practice in universities, laboratories, factories, and workshops (their benefits aside) continue to reinforce the dominant lessons of the $17^{\text {th }}$ century regarding matter, motion, time, and their relationship to mind or consciousness. The above referenced process based insights into the apparent

\footnotetext{
${ }^{1}$ Using either the word 'organism' or 'environment' without qualification results in a default interpretation that continues to support a dualistic framework of "subject before an object in space" (see Rosen, 2004). Throughout the present work these terms are understood through Dewey \& Bentley's (1949) transactional view that holds they cannot be understood as separate but as moments in a relationship.
}

The International Journal of Interdisciplinary Social Sciences

Volume 5, Number 3, 2010, http://www.SocialSciences-Journal.com, ISSN 1833-1882

(c) Common Ground, Chris Francovich, All Rights Reserved, Permissions:

cg-support@commongroundpublishing.com 
nondual nature of the cosmos are, in my view, among the most significant ideas and theories that human beings have yet developed.

The persistent difficulty in the spread and utilization of these ideas in human practices is, it is argued here, rooted as much in the structure and nature of reflective human awareness, or what is defined here as human consciousness, as it is in the processes of socialization, marginalization, and historical framing. Language itself - not primarily as a system of signs or of denotative and connotative meanings or communications, but as an effect on the underlying processes and functions of the whole human organism by its nature divides human awareness into a binary and potentially alienated stance toward the larger wholeness of experience. Drawing on Mead's work, and interpreting the creation of the reflective self as consequence of the evolutionary processes resulting in the significant symbol, the claim that the 'nature' of language creates a unique type of perspective ${ }^{2}$ resulting in the dualism inherent in subject/object relations is plausible.

The purpose of this paper is to establish a relevant, practical, and accessible bridge between the literature and theorizing of the nondual and dual using the general theoretical framework offered by George Herbert Mead. Mead's work is here related to literatures encompassing developmental theory, religious experience, and social theory. This paper explores claims about the separation of the dual and nondual with an effort toward understanding how to mitigate the divisive - often negative, and conditioned or habitual consequences of this phenomena so as to incorporate into the ordinariness of daily life the integrative and emergent skills and lessons of nondual experience.

\section{What is the Nondual?}

The primary concept upon which this paper turns is the Meadian notion of the social self (Mead, 1934; 1932/2002; 1938) and its necessary bifurcation of experience into the perceptual and conceptual world - a world of subjects and objects; a world with space independent from time and time from space. In his extended discourse on space, time, and social experience Mead (1932/2002) noted that “...in the perceptual world space and time are necessarily separate. Space-time ${ }^{3}$ cannot be the form of perceptual experience" (p. 156). His argument is essentially that the emergence/creation ${ }^{4}$ of the 'self' through the evolution of the human organism and of language necessitated the breaking up of experience into the contact experience ${ }^{5}$ of immediate haptic/sensory involvement and the abstracted and languaged perceptu-

\footnotetext{
${ }^{2}$ Perspective is a specifically Meadian (and Whiteheadian) term that is used here to illustrate the variety of perception types and awareness types that are possible in the organic world. One can have, it is argued, a nondual perspective. However, this concept, like the 'one-sided boundary' of Goudsmit (1992) does not admit to the reflective observer. So, for example, I may be allowed to talk about the perspective of a 'worm' but can in no way project my perspective on its perspective.

${ }^{3}$ Note that the words space-time with a hyphen refer to the Einsteinian notion of spacetime. When space and time are separated with the conjunction 'and' it refers to the ordinary experience of objects in a space before a subject (Rosen, 2004. p. 21)

4 The difficulty in talking about Mead's work is nowhere more apparent than when talking about 'objects' as substantial entities. For Mead the object is created by reflective human experience or consciousness. What is 'actually' happening is thought to be a continual emergence of patterned forms with varying degrees of stability or duration. For Mead the 'self' is both a body or person and a psychological phenomena - and both are continuously emergent. 5 It would be more accurate from my perspective to say 'contact awareness' as I interpret the word experience to suggest the conceptual involvement of reflective consciousness. However, Mead used this term so I will use it throughout.
} 
al/visual experience of what he termed 'distance experience'. My interpretation of Mead suggests that this is the condition of human experience - that we simultaneously inhabit space-time (with our bodies) and space independent of time (with our reflective consciousness). Mead's (1938) articulation of the processes underlying consciousness and identity clearly link the contact ${ }^{6}$ experience of the organism (all organisms) with the distance experience presented through language but probably developed along the entire line of evolution. The threshold between the contact experience of the person as organism and the distance experience of the person as social being is the context for this paper. Mead's work on the theory of emergence ${ }^{7}$ stands as one of the earliest post-Darwin efforts to create a coherent philosophical foundation for this phenomena (Mead \& Reck, 1981, pp. xiii-lxii). Certainly modern psychologists are interested in and study this phenomena of perception and attention at the interface of experience and conscious awareness (McCormick, 1997).

Ideas of the nondual/dual distinction are grounded in physical/biological science, philosophy, and the social sciences. From a physical perspective the work of Einstein and Bohr, and more recently Barad (2007) and Robert Rosen (2000) stand as exemplars in the realization that the idea and experience of dualism is insufficient. Whitehead (1938, pp. 127-147) articulated the need for a renewal of both science and social thought to match the insights that physical scientists developed in their inquiry into the nature and origins of 'matter'. Steven Rosen's (2004) extended treatise on the topic of the alienation of human reflective consciousness from Apeiron or the primordial and continually emergent cosmic flux chronicles the rise of science and human reflective consciousness. Dewey and Bentley (1949) demonstrated the essentially nondual nature of organism/environment relations or transactions. This philosophical ground on nondual nature of existence and the possibility of dissolving the divide has been tilled through process metaphysics (Rescher, 1996; Whitehead, 1978), philosophies of embodiment (Lakoff \& Johnson, 1999; Varela, Thompson, \& Rosch, 1991) and spiritually oriented treatises (Buber, 1970; Muller-Ortega, 1989). Psychology has been enriched in this area by the work of Piaget, (1971) and Vygotsky (1978;1986), and especially through work in ecological psychology (Heft, 2001; Reed, 1996).

Given that, from Mead's perspective, the experience ${ }^{8}$ of the nondual is, if not impossible, then very difficult to conceive we are left with few choices. We can abandon the project of penetrating this mystery, we can approach it through an experiential and/or metaphysical perspectives, or we can try to understand it from a scientific point of view. This paper will take the latter two approaches. First, I will engage in a brief discussion of the scientific point of view using ideas of the nondual based in physics and biology and second, discuss tech-

\footnotetext{
${ }^{6}$ See especially Mead's Philosophy of the Act (1938) for an extended discussion of the relationship between contact experience, distance experience, and the phenomenology of the self.

${ }^{7}$ Emergence is an extremely problematic concept interpreted from a variety of angles. The most common positivist interpretation is that complex systems express emergent processes resulting in state or phase changes that produce qualitatively different phenomena (e.g., water emerges from the interaction of hydrogen and oxygen). This is also the familiar 'the whole is greater than the sum of the parts' conversation. Emergence as used here is my interpretation of both Mead and Whitehead that gets to its continuous processual qualities that would have everything always in a process of emergent flux. Time, perspective, and substance are all evolved qualities that feedback on emergence and more or less serve to stabilize the process for the particular organism resulting in a continuous prehensive sense of 'being'.

${ }^{8}$ The term 'experience' is, of course, problematic. In this paper it refers to the felt and/or realized activity of a person with reflective consciousness. As mentioned above Mead (and others) tend to conflate it with the notions of both awareness and reflective consciousness.
} 
niques or practices that may shed some light on the metaphysical experience of this phenomena. The ultimate trajectory of this argument is toward the view of the continuous emergence and adaptation of the self/environment process as a simultaneous physical and psychological experience.

It is also important to note the phenomenological tradition has also supported this type of inquiry although Crotty (1998. pp. 78-86) argues that it has itself (at least in North America) retreated to a formal objectivist view of reality privileging the solitary thinking organism (person) to be the sole interpreter of the unproblematic object. If interpreted in the light of European phenomenology (Dreyfus, 1991: Merleau-Ponty, 1962) and taken as a serious practice of trying to penetrate the depths of the nondual absent language (reflective consciousness) then I see no fundamental inconsistency with those ideas and much of the thesis argued here.

\section{Physics \& Biology}

The postmodern tendency to label science as objectivist, positivist, and reductive certainly has merit given the track record of scientific endeavor in the last three hundred years. This is particularly true of organized 'corporate' science that is practiced to achieve pragmatic, economic, and/or utilitarian ends. The market seizes scientific insights and discoveries and transforms them into commodities which in turn reinforce the unproblematic concretization of subject/object relations. However, another kind of science is also practiced. This interdisciplinary science recognizes the complex, emergent, and relational nature of phenomena and has developed both biological and physical theories ${ }^{9}$ to accommodate the empirical experience/observation of phenomena (Jarvilehto, 2009; 1998a; 1998b).

The biophysicist Robert Rosen (2000), for example, writes about the fundamental noncompressibility or non-reduction of biological entities into rational algorithms or models. He observes that mathematical and structural linguistic efforts to capture the complexity of life are doomed to failure.

A system is called complex if it has a nonsimulable model. The science of such complex systems is very different from the science we have become used to over the past three centuries. Above all, complex systems cannot be completely characterized in terms of any reductionistic scheme based on simple systems. (p. 306)

Rosen's critique of both mimesis and reductionism as explanatory causal factors of phenomena invalidate claims of ultimate legitimacy and primacy made from the perspective of the postpositivist and traditional scientific perspective. His work also suggests that understanding the self as a complex system would inevitably involve a reworking of our communicative practices.

Maturana (1978) and Maturana and Varela $(1980 ; 1987)$ developed autopoiesis as a method and framework for describing and explaining the emergence and stability of life from a perspective cognizant of the observer's crucial role in making meaning and as Maturana (1978) observes "we literally create the world in which we live by living it (p.

\footnotetext{
${ }^{9}$ I will not be talking about social science theories here as that is the object of the argument. It is precisely the problematic nature of language and social experience that occludes some of our thinking about what may be the likely substrate of our emergent forms.
} 
61)." Their work serves to integrate physical biological theory with the epistemological problems related to observers and observations and problematizes our interpretations of any biological system as expressing perceptual or intentional behaviors. There is an obvious intersection of autopoiesis and the work of Dewey and Bentley in their efforts to clarify the epistemological conundrums of subjects and objects in the context of nondual emergent phenomena (Mousavi \& Garrison, 2003).

Karen Barad $(2007 ; 2008)$ is a theoretical particle physicist and feminist scholar who has developed the philosophy of Neils Bohr into a posthumanist account of the two moments of 'matter' and 'meaning' as reflective of an entangled wholeness in a state of continuous emergence. Her notion of 'agential realism' captures the paradox of the observer and the observed by means of the argument that relationship precedes relata (Barad, 2008) and that we as individuals/organisms are in a flux of continuous emergence that is fundamentally nondual. Similar to Cooper's (2005) analysis of relationships between individuals (relata) emerging out of latent structure in a complex background of process (not substance) our consciousness of objects is itself the measure of our alienation from the whole.

From a physical and traditional perspective what is most astonishing are the ubiquitous patterns of binary relationships that undergird scientific description. From the dual nature of matter and energy, to sexual differentiation and dimorphism, to information theory, we see oscillation between antimonies at every level of scale. In each case it appears that one pole of the relationship calls out or signals to the other pole to, at the very least, create a movement. The cascade of these movements eventually appear to result in the complex phenomena of organisms and human behavior. A radically different but coherent theoretical and empirical investigation into these biological and psychological phenomena has been occurring in the area of ecological psychology for a number of years. This is an important movement in that the bulk of our social science theorizing is built upon assumptions drawn from a psychology that is fundamentally representationalist and reinforces and subtly prejudices thought and language from recognizing the transactional and nondual relationships direct experience suggests.

\section{Ecological Psychology \& the Affordance}

Work in the area of ecological psychology (Good, 2006; Heft, 2001; Ingold, 1996; Reed, 1996a; Reed 1996b) takes a closer look at perception/environment relations based on a theoretical framework mostly articulated by Gibson $(1966 ; 1979)$ and Barker (1968). In this work perception is an active exploratory function utilizing distal information in a continuous organism/environment involvement mediated by transactional mediums, surfaces, and substances (Gibson, 1979). From Barker's (1968) and Reed's (1996) perspective the behavioral and conceptual consequences of these processes (reflective consciousness) is the mediation occurring in social or 'behavior' settings. The theorized element/process of this mediation of individual-to-setting or individual-to-individual or even setting-to-setting ${ }^{10}$ is the affordance.

\footnotetext{
${ }^{10}$ The notion of setting to setting mediation is problematic but can be made sense of using post-humanist accounts offered by, for example, Barad 2007, 2008 from a physical perspective and Latour, 1996 from a social perspective. The general notion here is that the elements or the relata 'fit' in a seamless and mutually instantiating manner. For example, a fallen tree in the woods 'fits' the ground (and the ground 'fits' the fallen tree) as a site for the mutual interaction/transaction of the biome/organism process of transformation.
} 
A central and much argued about idea in ecological psychology is that of the affordance (Jones, 2003). The affordance is a hybrid concept ${ }^{11}$ combining the physical world with the world of molar human behavior. Heft (2001) describes Gibson's description of the affordance as having “...perceiver-specific qualities and also is a property of the environment. From the point of view of the objective-subjective dichotomy, such a property is incomprehensible (p. 125)." Stoffregen (2003) defines affordances as "properties of events in the animal-environment system" (p. 35). What emerges from the organism-environment transaction (see Altman \& Rogoff, 1987) are properties that exist only as a function of that transaction. For example, the smoothness of water required for a bird to slow its motion for controlled landing is not necessarily 'smooth' to the gnat or fly. This property which 'affords landing' is emergent, contextual, and perspectival. Initially the affordance can been seen as a persistence in the organism's environment that serves to regulate its behavior. It can also be understood as an 'opportunity for action'. Affordances as properties can become significantly embodied in artifacts. For example, a chair affords sitting in a much more accommodating way than a lamp post. In the same way a restaurant affords multiple actions associated with eating and visiting. Culture, language, and history collaborate to create a landscape of affordances that take up most of our time and attention. We become engaged/entangled in our world via the inescapable necessities of our afforded environment. Baron (2010, pp. 250-255) usefully distinguishes between social and non-social affordances to help interpret and translate personality and other common dispositional characterizations about people into this non-traditional psychological frame.

From a Meadian perspective I interpret the affordance as both the source of contact experience and the link to distance experience. Contact experience as I understand it is the organism's pre-reflective-consciousness experience of the sensory world. We share the ecological environment of contact experience with all organisms. What language has brought us (according to Mead) is the opening up of the temporal and spatial landscape into 'distance experience' that hold space and time as independent parameters that facilitate subject/object distinctions as well as relations. Our perceptions and conceptions of 'space' are extrapolations from our bodies' contact with the immediate physical and sensory environment - "The round solid coin in the hand is the ultimate fact of every oval of vision (Mead, 1938, p. 281) ${ }^{12}$. Even so our perceptions are not necessarily fair brokers of our landscapes affordances.

For example, what I may initially think about as near may turn out to be far (a function of distance experience or reflective consciousness). If I consider my hand resting on a table and feel the pressure of the table on my hand I am experiencing/considering the feeling of pressure (contact experience) and the consideration of my hand, arm, body, and the table, room, and space that surrounds me (distance experience). I continue to oscillate between the two modes until eventually I conceptualize the whole experience and it becomes one of reflective consciousness. The contact experience of what is 'near' (the pressure) is made distant or 'far' (the body, arm, table system) and the distant or 'far' is made 'near' through my action/decision to mitigate what I consider to be too much pressure, boredom with the experi-

\footnotetext{
${ }^{11}$ This is a hybrid in the sense it serves as both noun/verb simultaneously. It is a process/object kind of idea. The affordance is both a 'thing' and a 'happening'.

${ }^{12}$ From Mead's perspective the significant symbol gives rise to the self, distance experience, and the object in a continuous emergent expression. The argument supporting this claim and the background developed to make this argument make up what I understand as the major body of Mead's work. Obviously that entire argument cannot be recapitulated here.
} 
ment, or whatever other thought may encourage me to abandon the arm position under consideration. What is far can be understood as near ${ }^{13}$ as the distance experience of reflective consciousness is collapsed into the contact experience of the body. Under this reading the behavior of any organism can be understood as melded or continuously fused to the medium, surfaces, and substances of contact experience. The 'world' become a continuous and nondual medium of events in a process of continual emergence. The organism as such is a contingent fluid movement/event in the fluid movement/event of spacetime.

This only makes sense if one interprets the Meadian argument of the 'object' as an artifact of reflective consciousness - that is, language. Gibson's 'optic array' captures this thinking in his articulation of the organism's adapted navigational behaviors in a continuously unfolding awareness ${ }^{14}$ of ambient environmental information that only comes to 'exist' as such as the organism actively moves through the environment. We are in continuous contact with an ever fluctuating ecology occurring as a function of our activity. What our reflective consciousness perceives as distant are actually symbols or concepts standing in for the proximal interface of the affordance which is continuously enacted by our activity. What we consider as 'real' in all this are the artifacts of Mead's distance experience conceptualized as objects. These 'objects' include symbols, signals, marks on paper, and all other 'detectors' that humans have devised to talk about and think about the apparently proximal interface between stimulus in the ambient environment and structures at the surface of the organism. One might say that an empirical realist claim about the ontology of the object only becomes clear (or valid) when we are actually in contact with it.

It follows then that empiricism has been the effort to map the conceptual world of distance experience to the apparent 'realness' of contact experience. Science as commonly practiced has been a systematic attempt to forge these relationships. This project fell apart from an epistemological perspective in the latter part of the $19^{\text {th }}$ century when it became apparent that our experience of embodiment in the world was significantly rooted in reflective consciousness and the apparent or phenomenal separation of the subject from the object (or the self from the other) is actually a fiction. There is no 'out there' or 'in here' in space-time. It's all one 'thing' that is actually not a 'thing' but a process. What our science has unequivocally and progressively revealed is a seamless emergence - with organisms in continuous contact with the mediums, surfaces, and substances of the ecological array. Symbolic interactionism, existentialism, phenomenology, and the birth of interpretive embodied methodologies have developed to keep up with the findings of science that suggest a nondual wholeness out of which we, along with everything else, are continuously emerging. Certainly what remains problematic in this articulation is the problem of the self and consciousness and how and/or why we come to grips with this apparent alienation and transcend or reconcile the bifurcation that reflective consciousness suggests.

\footnotetext{
${ }^{13}$ Of course a major problem with the language of 'near and far' is that it assumes an ontological certainty of space as distance experience reveals it. Much of Mead's work is bent on showing how these concepts are relative to language and human consciousness and have no place in what he seems to think is the more primary world of relativity and spacetime.

${ }^{14}$ Awareness is also a problematic word. Here it is used to express the proprioceptive or prehensive feedback mechanisms that translate sensory stimulus throughout a biological system in a more or less regular or predictable way - for example the effects of 'cold' on a warm blooded mammal.
} 


\section{Boundaries, Identity, \& the Self}

\section{Embodiment Perspectives}

Support for Mead's basic premise of the social construction of the self is found in Vygotsky's (1978; 1986) and Leont'ev's (1978) work which underpins much of cultural historical activity theory (CHAT). While this stream of theorizing appears more concerned with activity and social interactions than with epistemological questions of the self, it nonetheless illuminates the dynamic and interactive coherence arising within the biological and cultural phenomena we study. Vygotsky (1986) offers a credible empirical account of the relationship between language and the emerging social identity and underscores the central role of language in human development. From Mead's perspective the development of the 'self' is also rooted in biological, evolutionary, and ethological interpretations of phenomena.

According to Mead, organisms entrain themselves to conspecifics through a conversation of gesture and response. The significant gestures (Mead's term) that organisms employ are happening on an evolutionary ladder of increasing coordination via communication amongst entrained interlocutors that eventually, and through the pressures of increased social complexity and evolved neurobiological structures, result in a 'phase shift' in communications (see Latour, 1996). This conversation of gestures, according to Mead, results in homo sapiens internalizing ${ }^{15}$ via the significant symbol first specific others (family) and then through a progressive process of role taking and role playing eventually come to the generalized other (Franks, 1985; Mead, 1934, 1938) and the creation of the reflective self. This internalized generalized other becomes the 'me' of reflective consciousness and is the beginning of the deep patterning that we come to know as our subjective selves. As a dynamic process and using the same functions of the central nervous system that afforded us the ability to develop increasingly complex gestures and responses suggestive of the 'me' we also find the "I". Mead asserts that their combination results in reflective consciousness: "The "I" reacts to the self which arises through the taking of the attitudes of others. Through taking those attitudes we have introduced the "me" and we react to it as an "I" (1934, p. 174)". Mead goes on to suggest that the "I" is elusive and can never really be grasped because when we land on it we can only do so via memory and it is then firmly lodged in the "me". In other words, the self takes on the attitude of the "I" in the form of the "me" just like it does the attitude of the other. While Mead suggests that substantive questions about the "I/me" relationship are metaphysical (Mead, 1934, pp. 173-178) it is clear that the sentient, aware, biologically and neurologically connected nature of organisms contains a locus or center of activity that is clearly not symbolically or linguistically self-reflective in the manner human beings are. Griffin (1989) following Whitehead's description of prehension as the phenomena of nonsensory perception explaining the enduring nature of structure in spacetime says,

This prehension is the receptivity... with which every occasion of experience begins. Panexperientialism implies that every actual entity enjoys perception in the sense of this nonsensory prehension. Sensory organs are not necessary, in other words, to per-

\footnotetext{
${ }^{15}$ The 'internalization of the generalized other' may seem like a kind of 'hand waving' move in Mead's theory if not understood through its neurobiological and evolutionary roots. Emerging theory and science on mirror neurons and the phenomena of synchrony and phased oscillators provide empirical evidence that this hypothesis of the creation of the significant symbol and the self has some objectivist scientific support.
} 
ceive, in the sense of prehend. It is therefore not absurd to attribute a type of perception to things such as cells, and even molecules, and electrons. They can perceive their environment, in the sense of "internally take account" of it. This position also implies, that, even in organisms with sensory organs, such as ourselves, sensory perception is a secondary, not the primary, form of perception. (p. 25 italics in the original)

Reed (1996, pp. 20-28) makes a very similar argument in recounting important but mostly forgotten empirical work by Charles Darwin demonstrating the awareness and apparently purposeful behavior of earthworms as they navigate and adapt to varying types of soil. It is in phenomena of this sort that I locate the "I" and count it as that which theoretically connects us to all life independent of human categories, identities, and words. Consequently we are all prehensively aware and this awareness sits behind language and continually advances both the self and language as the primary motive force of the organism.

The I/Me phenomenon of the reflective self locates our experience in what Mead called the 'specious present' or the peculiar juxtaposition of the past and future in the present to create a sense of continuous being. Mead (1932/2002) says: "We find here the fundamental relation between the future and the past in the present. The distance experience is the promise of contact experience (p. 65)." This phenomenological 'present' is, according to Mead, an artifact of reflective consciousness. To be aware of the specious present as a human being appears not to be synonymous with experiencing the present as an organism without reflective consciousness (Kentridge, Nijboer, \& Heywood, 2008; McCormick, 1997) or even as tested by an observer tracking a subject's conscious response to an applied stimulus. This illustrates the importance of making a categorical distinction between awareness and the experience of the self as a function of reflective consciousness

Stacey and others (Stacey, Griffin, \& Shaw, 2000; Stacey, 2001; 2003) following Mead and utilizing the process sociology of Elias (1991) argue in a compelling set of books for an interpretation of Mead that locates the Meadian 'self' in a dynamic emergent process that comprises the 'living present' (Mead's 'specious present) whereby reflective consciousness creates the symbolic world of spatial and temporal independence and thereby stabilizes the appearance of enduring subjects before static and/or dynamic objects (artifacts of reflective consciousness) in a timeless space regulated or metered by a spaceless time. Further, that the patterns continually enacted by self-reflective consciousness operate out of gesture/response dynamics and emerge as inclusive boundaries to selves, groups, and societies which in turn instantiate exclusive power relations. These power relations are a concomitant of the boundary creation and are necessary for reflective consciousness to sustain its identity over against the identity of its objects. This of course suggests Foucault's (1994) and other's interpretations of how discourse structures social life.

\section{Objective Perspectives}

More or less traditional social psychology approaches in exploring the relationship between the subjective experience of individuals and the macro behaviors and processes of organizations and groups are found in personal identity, social identity, and social categorization theory (Postmes \& Jetten, 2006). On the other hand, positioning theory (Harré \& Moghaddam, 2003 ) is an effort to encompass the complexity of dynamic human behavior in groups that is sensitive to local, cultural, and idiosyncratic phenomena. This work is methodologically 
satisfying in exploring self and group relationships but does not appear to directly discuss the phenomenology and origins of the self in detail.

The psychology and neuroscience of attachment (Mikulincer \& Shaver, 2007; Siegel 1999) does attempt to reason from the singular biological case and explore the neurobiological consequences of relational bonding. Securely attached infants and toddlers are thought to be better 'socialized' than the non-securely attached in their approach to the "strange situation" (Siegel 1999, pp. 67-120) involving unknown but social others. Secure attachment is also thought to be implicated in a host of other body states involving emotion, metabolism, and general physiological functions as they relate to social experience. There is some evidence that a lack of relational bonding results in altered brain physiology and function (Siegel, 1999, pp. 317-320).

In both of these objectivist traditions the effort is toward understanding and, to some extent, operationalizing the relationship so as to develop stable units of analysis for empirical work. This research is typically achieved through a perspective that holds the observer as nonproblematic and generally is 'about' people or things as objects and not taking into account a direct experience of people or things intersubjectively. A bridge between the objectivist approaches mentioned above and the embodied and/or non-objectivist traditions can be found in current work on the neuroscience of meditation practice and its linkages to attachment and relationship (Hölzel, et. al., 2008; Kozasa, et al., 2008; Lutz, Dunne, \& Davidson, 2007; Siegel, 2007). To achieve this latter perspective we need to further shift our methods and begin to explore the $1^{\text {st }}$ person subjective techniques for penetrating consciousness and the nature of experience and awareness.

\section{Metaphysics and the Nondual}

Organizational theorist Chris Argyris (1999) is partly famous for observing that espoused theories and theories in use are often worlds apart. The perennial problem of consistency, integrity, 'walking one's talk' and generally acting or doing what we want and intend to do is of central concern to theorists in my field of leadership studies. What this paper offers is a theoretical framework and warrant for including in theoretical investigation the work of a 'practice' or of paying attention to one's own consciousness, behavior, and experience in a very direct way. Obviously there are many diverse means to this end. One means discussed here and linked to the literature above is the practice of meditation. One type of meditation, Vipassana, will be discussed but is by no means the foremost or ideal of reflective or selfawareness practices.

Buddhist psychology (Kornfield, 2008) is the term for a growing field of studies that combines classical Buddhist teaching and practice with western conceptions of the self, the mind, and the experience of being human. It has become part of what are known as 'mindfulness practices' (Wallace \& Shapiro, 2006) and is used therapeutically and is also researched in psychology and neuroscience contexts (Epstein, 1995; Lutz, Dunne, \& Davidson, 2007). Fundamental to the practice of mindfulness is the intentional altering of brain states to, for example, reduce stress and anxiety or otherwise change a person's qualitative experience of being alive. 


\section{Suffering and the Pathologies of the Dual}

The Buddhist interpretation (Bodhi, 2005) of the above mentioned brain states and the reason for 'altering' them is rooted in the fundamental theoretical framework of the 'illusory self' or that invented and concretized world of objects and their relationships. This reading is consistent with Mead's analysis though his lacks the normative and prescriptive injunctions of Buddhist philosophy. In Buddhism it is thought that with increased practice of meditation this illusory self will disappear and along with it the suffering that its attachment to both itself and its objects generates. In Buddhist terms this suffering is the result of believing that the artifacts of reflective consciousness (i.e., its conceptions and perceptions) are mistakenly attributed to be 'real' in the face of the continual change and transformation of the underlying nondual 'reality'. Our attachment to the 'appointed' permanence of 'things' is doomed to “disappointment” (Trungpa, 1976/1988, pp. 5-7).

From a Meadian perspective things look much the same. The disjunction between the socially constructed world of reflective consciousness and the continual emergence of contact experience creates a dissonance that manifests itself in a variety of ways. Implicit in what is argued here is that the imbalances and dysfunctions of contemporary global cultures are related to the patterns of behavior suggested either by Buddhist teachings around suffering or the more secular argument based on Mead. Attachment, aversion, and delusion are thought to be the inevitable consequence of the habitual and increasingly unaware processes underlying the human condition - the simple state of reflective human consciousness - knowledge of the self and other.

\section{Meditation Practice}

Vipassana meditation in the Buddhist tradition illustrates key principles explored in this paper. Of particular interest is the practice of 'noble silence'. This practice occurs in a mediation retreat setting where both speech and gaze are withheld (the "noble silence' ${ }^{16}$ ) for varying numbers of days while numerous individuals abide in close proximity engaging in cycles of sitting meditation. The dynamic that results in terms of subjective experience and ideation appear to substantiate in a direct way the fact of the "internalized generalized other" offered by Mead and its relationship to contact and distance experience. This also illustrates the role of the 'affordance' in playing a role of habitually reinforcing expectations and behavior in a social environment.

It has been my experience ${ }^{17}$ that the intentional withholding of verbal and visual stimulus begins a process of unintentional ideation around the nature of others and the meaning of their nature in reference to my own immediate experience. I have experienced over the course of 6 years several mediation retreats from 4 to 10 days duration. In all of these retreats I experienced numerous and elaborate projections and fantasies composed of a variety of thoughts and ideas that often seemed wholly inconsistent with what I believe and who I think I am.

\footnotetext{
${ }^{16}$ This interpretation and characterization of 'noble silence' was what I learned from a Zen Buddhist teacher in one of my first mediation retreats. I should also note that at this very first retreat I decided to take this injunction very seriously and apply the 'noble silence' rigorously. I since came to find that not everyone took the teacher's advice so seriously. The term is used somewhat differently in the literature on Buddhism to describe the aspects of 'right speech' and refraining of speaking of things best not (or unable to be) said.

${ }^{17}$ This paper is not a thorough study of my (or anyone's) experience of meditation or dialogue per se. The vignettes offered here are for illustrative purposes only.
} 
I invented and spontaneously created stories, reasons, and social realities in the absence of any direct visual or aural/linguistic stimulus. Over time the meditation (especially in the 10 day retreats) settled these often chaotic projections down. My understanding of this phenomena is that the habitual self is maintained by frequent social interactions that are particularly stimulated by conversation and visual facial stimulus of others both of which are part and parcel of the gesture/response dynamic. We create habitual and reflex type associations that manifest themselves as thoughts (Bohm, 1992, pp. 118-120). Social categorization theory and social identity theory (Postmes \& Jetten, 2006) both articulate the dynamics of maintaining a sense of identity in groups and suggest that our subjective sense of self is dependent on these social norms and are cued and instantiated through social interaction.

My experience is that both verbal and visual cues (e.g., me explicitly or implicitly telling people who I am and me seeing them seeing me) help stabilize my familiar sense of self through the multiple gestures and responses of daily life. When we intentionally interrupt these 'natural' processes we become aware of the 'other' in the self in the form of projections and specific fantasies about the other absent any concrete information. For example, in most cases the retreat begins without participants getting to know one another or even in some cases really get a good look at the face of another. Once the retreat begins and the 'noble silence' is enacted you don't see the face or interact with the other except as a fellow body in the process of walking to the dining hall, your room, or the meditation hall. And yet I found myself creating images, stories, and/or 'identities' of these others that were quite elaborate and full of affect and meaning to me. I also realized that I was doing this absent any real information or knowledge of the other. This was and is a profoundly affecting experience that can only be reasonably explained (in my opinion) using a theory of the self as outlined here by Mead. For me the meditation experience has, over time, revealed habitual patterns of ideation and ways of interacting with others. There is some indication that this awareness of habitual patterns can be substantiated empirically with brain-imaging techniques showing how the structure of neurons in the prefrontal cortex (structures associated with ideation around habitual or repetitive behaviors) are altered through meditation (Siegel, 2007 , pp. 355-358). Self reports indicate a subjective state of enhanced receptivity and awareness around the triggering behaviors and observers report subjects as more present and exhibiting a 'kinder' affect (Siegel, 2007, pp. 31-32; pp. 337-362).

What is encountered as a result of this disengagement from unconscious/unaware social engagement is, of course, the focus of Buddhist (and other) practices and is often conceived of as the beginnings of an experience of the nondual. In the context of this paper it is the 'experience' of non-reflective consciousness, or as I have defined it, awareness. What these reflections suggest is that there are 'practices' that can be employed to probe the boundaries of the nondual and the dual and that the 'fruits' of these practices may result in a progressively greater awareness that has as a probable consequence the enlargement of the specious present. This, I contend, can result in kinder, more thoughtful, respectful, and curious people insofar as they are aware and mindful of their complex social roles.

\section{Conclusion}

The argument as laid out here suggests that there is an empirical scientific and phenomenological basis for better understanding the origins and effects of reflective consciousness on experience and behavior and that that empirical scientific and phenomenological basis is 
confirmed and further explicated by an intentional "practice" (in this case Buddhist meditation). Both of these perspectives may be necessary to sufficiently understand and work with the challenges that the ecological juxtaposition of embodiment and reflective consciousness bring. Our compelling but apparently illusory belief in the 'objective' and solid nature of the world has obviously been a mixed blessing. On the one hand it gives us the tools and talents of communication, aesthetics, and technology. On the other hand it has harmed (and continues to harm) our ecological and social environments. Our persistent belief in the 'reality' of the self and the other as distinct, separate, and often alienated beings appears to damage the integrative forces of collaboration, community, and the development of loving and caring personal and social relations (Noddings, 1984) .

The work of George Herbert Mead is a valuable and underutilized body of thought that can serve to help articulate and demonstrate the nature of our reflective consciousness and its relationship to the phenomenal world that is apparently continually emerging in a field of space-time with quantum effects holding together the emergent patterns that we experience as matter and meaning. Practices such as Vipassana meditation can also work to help individuals loosen the hold that sociality and reflective consciousness have on our cognitive and affective states as active living beings in order to more gracefully and peacefully negotiate the boundaries, power relations, and identities sociality implies. Awareness of these ideas and practices may bring humans into a closer more continuous relationship with the ongoing adaptation of the human organism with the ecological environment. Rather than consciousness distancing us from our natural world, we may use it to forge more enduring links to root our experience in sustainable and generative practices. The irony of the meditation experience is that it (and many other forms of devotion, contemplative, or scholarly practice) may temporarily remove its practitioners from sociality but serves, in the end, to make its practitioners even more equipped and capable for meaningful and caring social interaction.

\section{References}

Argyris, C. (1999). On organizational learning. Malden. Massachusetts: Blackwell Business.

Altman, I. and B. Rogoff (1987). World Views in Psychology: Trait, Interactional, Organismic, and Transactional Perspectives. Handbook of Environmental Psychology. D. Stokols and I. Altman. New York, John Wiley \& Sons: 7- 40.

Barad, K. M. (2007). Meeting the universe halfway: Quantum physics and the entanglement of matter and meaning. Durham: Duke University Press.

Barad, K. (2008). Posthumanist performativity: Toward an understanding of how matter comes to matter. in Alaimo, S., \& Hekman, S. J., Material feminisms. Bloomington, IN: Indiana University Press. Chapter 4

Baron, R.M., (2010). Developing an ecological framework for establishing connections among dispositions, behaviors, and environments: From affordances to behavior settings. In Agnew, C.

R. Then a miracle occurs focusing on behavior in social psychological theory and research: Purdue symposium on psychological sciences (pp. 247-271). Oxford: Oxford University Press.

Barker, R. G. (1968). Ecological Psychology: Concepts and methods for studying the environment of human behavior. Palo Alto, CA: Stanford University Press.

Bodhi, B. (2005). In the Buddha's words : An anthology of discourses from the Pali Canon (1st ed.). Boston, Mass: Wisdom Publications.

Bohm, D. (1992). Thought as a system. New York: Routledge.

Buber, M. (1970). I \& thou (W. Kaufmann Trans.). New York: Simon \& Schuster. 
Cooper, R. (2005). Peripheral vision: Relationality. Organization Studies (01708406), 26(11), 16891710.

Crotty, M. (1998). The foundations of social research: Meaning and perspective in the research process. London ; Thousand Oaks, CA: Sage Publications.

Dewey, J., \& Bentley, A. F. (1949). Knowing and the known. Boston: Beacon.

Dreyfus, H. L. (1991). Being-in-the-world: A commentary on Heidegger's being and time, division I. Cambridge, MA: MIT Press.

Epstein, M. (1995). Thoughts without a thinker : Psychotherapy from a Buddhist perspective. New York, N.Y: Basic Books

Elias, N. (1991). The society of individuals. Oxford: Basil Blackwell.

Foucault, M. (1994). The birth of the clinic: An archaeology of medical perception (A. M. Sheridan Smith Trans.). New York: Vintage Books.

Franks, D. (1992). The self in evolutionary psychology. In Hamilton, P. (Ed.). George Herbert Mead: Critical assessments (Vol. IV, pp. 191-221). London: Routledge.

Gibson, J. J. (1966). The senses considered as perceptual systems. Boston: Houghton Mifflin.

Gibson, J. J. (1979). The ecological approach to visual perception. Boston: Houghton Mifflin.

Good, J. M. M. (2007). The affordances for social psychology of the ecological approach to social knowing. Theory \& Psychology, 17(2), 265-295.

Goudsmit, A. (1992). A one-sided boundary: On the limits of knowing organizational closure. In Van de Vijver, G. (Ed.), New Perspectives on Cybernetics (pp. 175-205). Netherlands, Kluwer Academic Publishers.

Griffin, D. R. (Ed.) (1989). Archetypal process : Self and divine in Whitehead, Jung, and Hillman. Evanston, Ill: Northwestern University Press.

Harré, R., \& Moghaddam, F. M. (Eds.) (2003). The self and others : Positioning individuals and groups in personal, political, and cultural contexts. Westport, Conn: Praeger.

Heft, H. (2001). Ecological psychology in context: James Gibson, Roger Barker, and the legacy of William James's radical empiricism. Mahwah, New Jersey: Lawrence Erlbaum Associates.

Hölzel, B. K., Ott, U., Gard, T., Hempel, H., Weygandt, M., Morgen, K., et al. (2008). Investigation of mindfulness meditation practitioners with Voxel-based morphometry. Social Cognitive and Affective Neuroscience, 3(1), 55-61.

Ingold, T. (1996). Situating action VI: A comment on the distinction between the material and the social. Ecological Psychology, 8(2), 183-187.

Järvilehto, T. (2009). The theory of the organism-environment system as a basis of experimental work in psychology. Ecological Psychology, 21(2), 112-120.

Jarvilehto, T. (1998a). The theory of the organism-environment system: I. description of the theory. Integrative Physiological \& Behavioral Science, 33(4), 321.

Jarvilehto, T. (1998b). The theory of the organism-environment system: II. significance of nervous activity in the organism-environment system. Integrative Physiological \& Behavioral Science, $33(4), 335$.

Jones, K. S. (2003). What is an affordance? Ecological Psychology, 15(2), 107.

Kentridge, R., Nijboer, T, \& Heywood, C. (2008). Attended but unseen: Visual attention is not sufficient for visual awareness. Neuropsychologia, 46(3), 864-869.

Kornfield, J. (2008). The wise heart : A guide to the universal teachings of Buddhist psychology. New York: Bantam Books.

Kozasa, E. H., Radvany, J., Barreiros, M. Â. M., Leite, J. R., \& Amaro, E., Jr. (2008). Preliminary functional magnetic resonance imaging stroop task results before and after a Zen meditation retreat. Psychiatry and Clinical Neurosciences, 62(3)

Lakoff, G., \& Johnson, M. (1999). Philosophy in the flesh: The embodied mind and its challenge to western thought. New York: Basic Books.

Latour, B. (1996). On interobjectivity. Mind, Culture, and Activity, 3(4), 228-245. 
Leont'ev, A. N. (1978). Activity, consciousness, and personality. Englewood Cliff, New Jersey: Prentice Hall.

Lutz, A., Dunne, J. D., \& Davidson, R. J. (2007). Meditation and the neuroscience of consciousness: An introduction. In E. Thompson (Ed.), The Cambridge handbook of consciousness. (pp. 499-551). New York, NY US: Cambridge University Press.

McCormick, P. A. (1997). Orienting attention without awareness. Journal of Experimental Psychology: Human Perception and Performance, 23(1), 168-180.

Maturana, H. (1978). Biology of language: The epistemology of reality. In G. A. Miller, \& E. Lennenberg (Eds.), Psychology and biology of language and thought: Essays in honor of Eric Lennenberg (pp. 27-63). New York: Academic Press Inc.

Maturana, H., \& Varela, F. (1980). Autopoiesis and cognition: The realization of the living. Dordrecht, Holland: D. Reidel Publishing Company.

Maturana, H., \& Varela, F. (1987). The tree of knowledge; the biological roots of human understanding. Boston, MA: Shambhala.

Mead, G. H. (1934). Mind, self, and society: From the standpoint of a social behaviorist. Chicago: University of Chicago Press.

Mead, G. H., \& Reck, A. J. (1981). Selected writings. Chicago: University of Chicago Press.

Mead, G. H. (1932/2002). The philosophy of the present. Amherst, N.Y: Prometheus Books.

Mead, G. H., (1938). The philosophy of the act. Chicago: Ill., University of Chicago Press.

Merleau-Ponty, M. (1962). Phenomenology of perception. New York: Humanities Press.

Mikulincer, M., \& Shaver, P. R. (2007). Attachment in adulthood: Structure, dynamics, and change. New York: Guilford Press.

Mousavi, S., \& Garrison, J. (2003). Toward a transactional theory of decision making: Creative rationality as functional coordination in context. Journal of Economic Methodology, 10(2), 131.

Muller-Ortega, P. E. (1989). The triadic heart of Siva : Kaula Tantricism of Abhinavagupta in the nondual Shaivism of Kashmir. Albany: State University of New York Press.

Noddings, N. (1984). Caring, a feminine approach to ethics \& moral education. Berkeley: University of California Press.

Piaget, J. (1971). Biology and knowledge. Chicago: University of Chicago Press.

Postmes, T., \& Jetten, J. (Eds.) (2006). Individuality and the group : Advances in social identity. London; Thousand Oaks, CA: SAGE.

Reed, E. S. (1996a). Encountering the world: Toward an ecological psychology. Oxford: Oxford University Press.

Reed, E. S. (1996b). The necessity of experience. Yale University Press.

Reed, E. S. (1998). From soul to mind: The emergence of psychology, from Erasmus Darwin to William James. New Haven CT: Yale University Press.

Rescher, N. (1996). Process metaphysics : An introduction to process philosophy. Albany: State University of New York Press.

Rosen, S. M. (2004). Dimensions of Apeiron : A topological phenomenology of space, time, and individuation. Amsterdam: Rodopi

Rosen, R. (2000). Essays on life itself. New York, NY: Columbia University Press.

Siegel, D. J. (1999). The developing mind: How relationships and the brain interact to shape who we are. New York: The Guilford Press.

Siegel, D. J. (2007). The mindful brain : Reflection and attunement in the cultivation of well-being (1st ed.). New York: W.W. Norton.

Stacey, R. D. (2001). Complex responsive processes in organizations: Learning and knowledge creation. New York: Routledge.

Stacey, R. D. (2003). Complexity and group processes : A radically social understanding of individuals. Hove ; New York: Brunner-Routledge.

Stacey, R. D., Griffin, D., \& Shaw, P. (2000). Complexity and management: Fad or radical challenge to systems thinking? London: Routledge. 
Stoffregen, T. (2003) Affordances are enough: reply to Chemero et al. Ecological Psychology 15(1): 29-36

Trungpa, C. (1976/1988) Baker, J., \& Casper, M. (Eds.). The myth of freedom and the way of meditation. Boston: Shambhala

Varela, F. J., Thompson, E., \& Rosch, E. (1991). The embodied mind: Cognitive science and human experience. Cambridge, MA: MIT Press.

Wallace, B. A., \& Shapiro, S. L. (2006). Mental balance and well-being: Building bridges between Buddhism and western psychology. American Psychologist, 61(7), 690-701.

Whitehead, A. N. (1978). Process and reality: An essay in cosmology. New York: The Free Press.

Whitehead, A. N. (1938). Modes of Thought. New York: The Free Press

Vygotsky, L. (1986). Thought and language. Cambridge, MA: MIT Press.

Vygotsky, L. S. (1978). Mind in society. Cambridge, MA: Harvard University Press.

\section{About the Author}

\section{Chris Francovich}

Chris Francovich is assistant professor in Gonzaga University's doctoral program in leadership studies. Chris' work focuses on the dynamics of the self-in-society and the implications of this interpretation on ethical, normative, and cultural practices. He is currently studying and researching narrative and the influence relationships between settings and people. Chris completed his undergraduate education at Gonzaga in 1980 with a business degree and an Ed.D from Boise State in 1997. His intellectual passion is interdisciplinary studies. Chris is also a senior research analyst for the Northwest Regional Faculty Development Center in Boise, Idaho. This work involves understanding individual and cultural aspects of postgraduate medical education in ambulatory medical clinics. Chris is also a research associate with the Reina Trust Building Institute of Stowe, Vermont. The Institute is devoted to building and sustaining trust in the workplace. 
Copyright of International Journal of Interdisciplinary Social Sciences is the property of Common Ground Publishing and its content may not be copied or emailed to multiple sites or posted to a listserv without the copyright holder's express written permission. However, users may print, download, or email articles for individual use. 